The Research Journal of the Costume Culture

[Original Article]

Received November 30, 2016

Accepted January 19, 2017

${ }^{\dagger}$ Corresponding author

(shpark@ks.ac.kr)

ORCID

Jeong-Min Lee

http://orcid.org/0000-0003-3894-996X

Sook-Hyun Park

http://orcid.org/0000-0002-0477-4076

Kyung-Lim Lee

http://orcid.org/0000-0003-2978-5334

\section{Impact on self-satisfaction of shopping tendencies and purchasing behaviors for luxury goods}

\author{
Jeong-Min Lee, Sook-Hyun Park ${ }^{\dagger}$ and Kyung-Lim Lee
}

Dept. of Fashion Design \& Merchandising, Kyungsung University, Korea

\author{
이정민 · 박숙현 ${ }^{\dagger} \cdot$ 이경림 \\ 경성대학교 패션디자인학과
}

\begin{abstract}
This paper aims to identify the impact on self-satisfaction of shopping tendencies and purchase behaviors for luxury goods. The research was conducted by survey method using questionnaires. The subjects of this study were female consumers from 20 to years old with a high purchasing capability for luxury goods. Using the statistics program SPSS 21.0, factor analysis, reliability analysis, one-way ANOVA, and multiple-regression analysis were executed. The analysis results are summarized below. For shopping tendency depending on ages, pleasure pursuit tendency showed insignificant difference in $40 \sim 50$ s, but significant difference in 20 30s. For the self-satisfaction, the interpersonal satisfaction showed the difference by age group, which was much higher in the respondents in $30 \sim 50$ s than those in 20 s. Individuality pursuit tendency and rational shopping tendency had impact on self-satisfaction and rational shopping tendency on interpersonal satisfaction in 20s. Pleasure pursuit tendency and rational shopping tendency had impact on self-satisfaction and interpersonal satisfaction and pleasure pursuit tendency on the economic satisfaction in 30s. Pleasure pursuit tendency had impact on self-satisfaction and economic satisfaction and rational satisfaction on interpersonal satisfaction in 40s. Pleasure pursuit tendency and rational shopping tendency had impact on self-satisfaction and interpersonal satisfaction in 50s. High quality had impact on self-satisfaction and economic satisfaction and practicality on interpersonal satisfaction in 20s. High quality had impact on self-satisfaction and interpersonal satisfaction in 30s. High quality had impact on interpersonal satisfaction in 40s. High quality had impact on all elements of self-satisfaction for the respondents in 50 s, practicality had negative impact on interpersonal satisfaction.
\end{abstract}

Keywords: shopping tendency(쇼핑성형), purchasing behavior(구매행동), self-satisfaction (자기만족도)

\section{Introduction}

최근 계속되는 경기침체에도 불구하고 고가 제품에 대한 수요는 계속되고 있으 
며, 남들이 갖지 못하는 제품을 소유하고 싶은 욕구 로 명품 브랜드 매출은 계속해서 늘어나고 있는 추세 이다. Lee(2016)에 따르면 해외명품 신장률은 2013년 $7.8 \%$ 에서 2014년 $10 \%$ 를 기록한데 이어 지난해에는 $18.1 \%$ 증가했으며, 2016 년 상반기에도 $17.2 \%$ 로 신장 세를 이어가고 있다. 이러한 명품소비증가 현상은 최 고급 소비시장을 타깃으로 하는 럭셔리 제품 위주의 명품 또는 비교적 값이 저렴하면서도 감성적 만족을 얻을 수 있는 고급품인 매스티지(messtige) 위주의 명 품을 소비시장에 선보임으로써 소비자는 저렴한 가 격으로 명품을 구매할 수 있는 기회가 많아졌기 때문 인 것으로 사료된다. 또한 자신을 위한 투자로 자기 만족을 얻는 가치지향형 소비계층인 20 30대 포미족 (for me族)들이 지속적으로 증가하고 있으며, 건강관 리와 외모에 관심이 높아 비교적 고가임에도 자기만 족을 위해 소비를 중시하는 새로운 계층인 어번 그래 니족(urban granny族)이 증가하고 있기 때문인 것으 로 분석된다(Lee, 2016).

과거 한국에서의 명품소비는 부유층들의 경제력 과시를 위해서였다면 현재는 중산층뿐만 아니라, 유 행에 민감한 젊은층에 이르기까지 확산되고 있다. 명 품은 개인의 삶의 가치나 자기만족을 높이기 위한 하 나의 수단으로 점차 변화하여 소비자들의 쇼핑성향에 도 영향을 미치고 있다(Online issue team, 2015). 최근 소비자들은 개인의 소비성향에 따라 가치적 소비뿐 만 아니라, 자신을 매력적으로 연출하기 위한 수단으 로써 고급제품을 사용하는 이중적 형태의 과시소비 성향을 보이고 있다(Bae, 2016). 이러한 맥락에서 볼 때 명품소비자의 소비성향은 주관적인 감정이 반영 된 개인적 차원의 특성으로써 자기만족도와 관련이 있을 것으로 생각된다. 그러므로 명품은 소비자들의 변화 욕구와 자기개성 표현욕구 및 타인과의 구별 욕 구를 충족시킬 수 있는 수단일 뿐 아니라, 명품의 소 비를 통한 심리적 부분에도 영향력을 미칠 수 있기에 자기만족도의 연구는 의의가 있다고 본다.

국내 명품 관련 선행연구는 명품의 정의 및 현황에 관련된 연구(Choi, 2001; Lim, 2015), 명품구매행동 및 태도에 관한 연구(Bae, 2005; Park \& Jeon, 2004; Yoon, 2013), 명품추구혜택에 관련된 연구(Choi, 2010; Piak, 2001), 연령별 명품의 구매행동에 관한 연구(Chae \& Rhee, 2005; Kim \& Lee, 2011; Lee, 2010; Lee,
Lee, \& Jung, 2003; Song, 2008), 명품패션 및 구매만 족도에 관한 연구(Hwang, 2016; Kim, 2006; Lee, Kim, \& Lee, 2004; Sung, 2012) 등으로 명품에 관한 직접 적인 이론 연구이거나 명품을 통한 일반적 만족도에 관한 연구가 대부분이었고, 명품 소비자의 쇼핑성향 과 구매행동 특성에 따른 자기만족도를 연령별로 살 펴본 연구는 미흡한 실정이다. Chae and Rhee(2005) 의 주관적인 계층의식과 해외명품에 대한 태도 및 구 매빈도의 관계를 조사한 연구 결과에 따르면, 연령, 문화수준, 경제력, 소비생활이 태도에 대한 영향력 있 는 변수임이 밝혀졌고, 실제구매에 영향을 주는 변수 는 소비생활 수준과 연령, 문화수준으로 나타나, 연령 별 연구의 필요성이 제기된다.

지속적인 소비불황에도 수입명품의 소비가 성장하 고 있으며, 차별화된 상품을 선호하는 가치소비가 증 가하고 있는 현 실정에 맞추어 연령별로 명품 소비자 의 특성과 명품 소비에 따른 만족도를 다각적인 측면 에서 연구해볼 필요성이 있다고 판단된다. 그러므로 본 연구의 목적은 연령별로 소비자의 명품쇼핑성향 과 명품구매행동이 자기만족도에 미치는 영향을 살 펴봄으로써 명품 브랜드에서 연령에 따른 표적시장 을 세분화하여 목표고객에 적합한 상품기획과 포지 셔닝 전략 수립 및 소비자 심리와 구매행동분야에 활 용할 수 있는 기초자료를 제시하는데 있다.

\section{Theoretical Background}

\section{The conception of luxury goods}

명품(名品)의 사전적 의미는 '뛰어나거나 이름난 물건, 또는 그런 작품'이다(“Luxury goods”, n.d.). 또 한 호화상품(豪華商品)을 대변하는 명품의 수식어는 사치스럽다는 뜻의 럭셔리(luxury), 최고급품(high end product), 프리미엄제품(premium product) 등을 의미 한다(Yang, 2013). 명품이라는 용어는 명품마케터들 이 럭셔리(luxury)가 의미하는 사치품과 고가품이라 는 뜻의 거부감을 줄이기 위해 사용된 명칭이기도 하 다(Kim, 2007). 과거 한국에서의 명품은 상류층의 상 징으로 호화사치품으로 불리며 호화사치품을 사용하 는 것은 부도덕함으로 여겨왔지만, 명성(名聲)과 명사 (名士)를 뜻하는 명품이란 말이 등장하면서 명품이 일상어로 퍼져나갔다(Lee, 2016). 
명품의 개념을 국내외 선행연구에서 살펴보면, Vigneron and Johnson(1999)은 하나의 상품이 고급 상품이 되기 위해서 단지 가격이 비싸거나 희소성이 있거나 최첨단의 기능을 갖춘 정도로는 부족하며, 그 이상의 가치를 소비자들이 느낄 수 있어야 비로소 명 품이라고 할 수 있다고 하였다. Nia and Zaichkowsky (2000)는 소비자가 지각하는 명품의 특성은 상류층 취향을 가진 상품과 고가격, 그리고 상품명이며, 최근 에는 고가의 수입브랜드를 명품이라고 말하고 있다 고 하였다. $\mathrm{Kim}$ (2002)은 상징적인 브랜드 아이덴티 티, 제품 자체의 뛰어난 품질, 디자인, 전통이 결부된 미적취향의 특성을 가지며, 높은 가격과 한정된 생산 으로 인한 희소성을 갖는 것이 명품이라고 하였다. Bae (2009)는 명품이 정교하고 아름답게 만들어지고 고가 의 엘리트주의적 상품을 뜻하지만 패션명품은 해외 유명 컬렉션에서 발표된 브랜드들 중 패션전문 매거 진에서 품질을 인정받은 고가브랜드제품을 의미한다 고 하였다. 이와 같이 선행연구의 내용들을 살펴보면 명품은 품질을 인정받은 고가브랜드제품으로 고품질, 고가격, 최고급 소재, 질 높은 제작공정, 절제된 디자 인, 소량 생산의 희소성, 브랜드 아이덴티티, 장인정 신, 클래식한 전통, 명성, 권위 등을 지닌 제품을 의미 한다.

\section{Luxury goods shopping tendency}

쇼핑성향이란 소비자가 쇼핑 전과 쇼핑 시 나타나 는 포괄적인 태도와 행동으로 나타나는 쇼핑스타일이 다(Choi, 1996). Solomon(2002)은 쇼핑에 대한 일반 적인 태도를 쇼핑성향이라고 정의하였고, $\mathrm{Kim}(1999)$ 은 쇼핑성향을 소비자의 실제 제품 구매를 위한 행동뿐 만 아니라, 여가 선용적 행위를 포함하는 다차원적인 측면을 지닌 쇼핑 행동으로 정의하였다.

쇼핑성향에 관한 선행연구를 살펴보면, Jeong(2000) 은 쇼핑에 관하여 나타나는 소비자의 태도와 행동, 의 견을 포함하는 쇼핑형태를 유행비교 쇼핑성향, 경제비 교 쇼핑성향, 유행창조 쇼핑성향이라고 분류하였다. Lee(1998)는 쇼핑성향을 쾌락지향성, 상표지향성, 저 가지향성, 유행지향성, 효용가치지향성의 5 개 요인으 로 분류하였으며, Ryu(2000)는 쇼핑성향을 쾌락적 쇼 핑성향, 계획적 쇼핑성향, 충성적 쇼핑성향, 편의적 쇼 핑성향의 4 개 요인으로 분류하였다.
명품소비자의 쇼핑성향에 관한 선행연구를 살펴보 면, Lee and Choi(2001)는 과시추구형, 유행추구형, 독특성과 개성추구형, 감성적 즐거움 추구형, 합리적 추구형으로 분류되었다. $\operatorname{Kim}(2006)$ 은 20대 이상 여성 을 대상으로 효율성 추구쇼핑성향, 여가향유 추구쇼핑 성향, 편의성 추구쇼핑성향으로 분류되었다. Yoon and $\mathrm{Han}(2008)$ 은 20살 이상의 성인여성을 대상으로 독특 형, 자기과시형, 자아확장형, 품질지향형으로 분류되 었다. Lee(2010)는 20 30대 남녀를 대상으로 쾌락추 구 쇼핑성향, 유행추구 쇼핑성향, 독특성 추구 쇼핑성 향, 계획성 추구 쇼핑성향, 유명상표지향 쇼핑성향, 경제성 추구 쇼핑성향, 과시적 성향의 총 7 개 요인으 로 분류되었다.

이와 같이 쇼핑성향에 관한 선행연구 고찰 결과 쇼 핑성향의 구성요인은 연구자에 따라 다소 다르게 분 류되었다는 것을 알 수 있었다. 이러한 선행연구를 살 펴볼 때 명품 쇼핑성향의 구성요인은 독특성과 과시 성을 나타낼 수 있는 명품특성에 영향을 받아 일반쇼 핑성향과는 차이점이 나타난 것을 알 수 있다.

\section{Luxury goods purchase behavior}

구매(購買)의 사전적 의미는 물건을 사들이는 것으로 써 구매 계획, 구매 시기, 구매 장소, 구매 방법을 고려 하여 최종 소비자가 소비를 목적으로 구매하는 것이다 ("Purchase", n.d.). 구매행동이란 소비자들이 제한되고 불충분한 구매력을 가지고 그들의 욕구를 충분히 만족 시켜 줄 수 있는 서비스나 제품을 교환하는 과정에 관 여하는 사람들의 구매와 소비에 관련된 활동을 총칭한 다(Shin, 2000). 또한 소비자들이 자신이나 가족 혹은 타인을 위한 여러 가지 제품 구매 시 구매 당시의 특정 한 욕구(needs)를 충족시키기 위하여 재화나 서비스 획 득에 관련된 의사결정과정에서 나타나는 정신적 - 육체 적 행동과정이라고 할 수 있다(Kim, 1993). 이와 같이 소비자들은 동일한 환경에서 제품에 대한 다양한 서비 스나 마케팅을 접하더라도 개인의 욕구, 기호, 흥미, 가 치관 등에 따라 서로 다른 구매행동을 가진다.

명품구매행동에 관련된 선행연구를 살펴보면, Choi (2001)의 연구에서는 패션명품에 대한 소비자의 태도 가 패션명품 관여도, 우수한 품질, 패션명품 소비에 대한 부정적 반응, 패션명품 소비의 즐거움, 명품의 사치성, 패션명품의 전통적 가치, 패션명품의 희소성 
으로 나타났으며, 연령이 낮을수록 그리고 소득이 높 을수록 패션 명품이 갖는 품질의 우수성을 알고 인정 하는 경향이 높으며, 이와 함께 패션 명품에 대한 관 심이 높은 것으로 나타났다. Lee et al.(2003)은 여성 소비자들의 해외유명브랜드 선호도와 구매행동 연구 에서 명품 구매행동의 특성이 실용성과 고급성 순으 로 나타났으며, 해외유명브랜드를 선호하는 이유로는 고급, 품질, $\mathrm{A} / \mathrm{S}$, 디자인으로 나타났다. 또한 25 27세 집단이 고급스러움에 대한 선호도가 높았으며, 명품 을 구매하는 이유로는 디자인, 브랜드 이미지, 희소성, 자기과시 순으로 나타났다. $\operatorname{Song}(2008)$ 은 성인여성의 소비가치에 따른 패션명품구매행동에 관한 연구에서 20 40대 여성의 패션명품구매동기로 고급성의 요인 이 가장 높게 나타났으며, 심리성, 기능성, 실용성 요 인 순으로 나타났다. Kang and Hwang(2011)은 소비 자가 명품을 구매하는 경우에 고려하는 제품평가의 속성으로 외재적 속성 중 원산지, 브랜드, 가격의 순 서로 중요하게 인식한다고 하였다.

위의 선행연구를 살펴본 결과 구매행동은 마케팅 활동의 방향을 설정하고 구매결정에 직접적인 제약 을 가하는 중요한 요인이 된다(Kim, 1989). 명품구매 소비자는 연령별로 구매유형에 차이가 나타났으며, 쇼핑성향과 제품특성의 다차원적인 요인들이 상호작 용하여 명품구매행동에 영향을 미친다는 것을 보여 주고 있다.

\section{Self-satisfaction}

자기만족(self-satisfaction)은 자기 자신이나 또는 자신의 행위에 대해 스스로 만족하는 일을 의미한다 (“Self-satisfaction", n.d.). 주어진 생활을 기꺼이 수용 하고 이에 적응하며, 만족스럽고 행복하다고 느끼는 감정이 바로 자기만족이며, 이는 장기간에 걸쳐 개인 의 가치관과 자아개념 등에 의해 복합적으로 이루어 진 개념이다(Kalish, 1975).

자기만족도에 대한 국내외 선행연구를 살펴보면 George, Mutran, and Pennybacker(1980)는 자기만족 도를 자신이 바라던 것과 실제 성취한 것을 비교하여 자신의 전반적인 존재 상태를 평가하는 것이라고 정

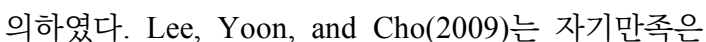
객관적 조건에 의한 일방적 규정이 아닌 개인 스스로 의 삶에 대한 기대수준에 의존한다고 하였고, 자기만
족에 영향을 주는 요인으로는 사회적 지지, 과거의 성취, 개인의 가치관, 의미 있는 사람의 존재 여부 등 이 있다고 하였다. Campbell(1997)은 자신의 삶에 대 한 만족 및 주관적 안녕이란 한 개인에게 있어서 그 가 가장 경험하고 싶은 수준과 현재의 생활조건 간의 비교에 의하여 결정되는 것이라고 하였다. $\mathrm{Cha(2001)}$ 는 자기만족도가 개인이 일상생활에서 주관적으로 느끼는 충족감 및 만족감과 관련된 의미로써 한 사 회의 구성원 개개인에게 주어진 삶의 상황과 주관적 삶의 질에 대한 어떠한 경험과 생각을 하고 있는가 를 의미하거나 개인이 자신의 삶에 대한 질적 수준 을 호의적으로 판단하는 정도라고 하였다. Park(2012) 은 자기만족도는 일상생활에서 느끼는 외모, 생활, 경 제, 대인관계와 관련하여 주관적이며 개인적인 만족 감과 관련한 의미로 정의하였다. $\operatorname{Park}(1991)$ 은 자기 만족도를 결정하는 요인은 수입, 교육, 결혼상태, 사 회적 활동 등이 있으며 가정내의 역동적 관계에도 영 향을 받는다고 하였다. 특히 노인층에서는 건강상태, 경제적 수준, 가족형태, 사회적 활동을 주요 요인으로 밝히고 있다. 이와 같이 선행연구에서는 자기만족도 에 대해 자신에 대한 생각, 감정, 가치, 태도, 긍정적 판단의 정도와 주어진 생활에 행복과 만족스럽다고 느끼는 주관적이며 개인적인 만족감을 바탕으로 한 사기(士氣), 행복, 적응, 심리적 복지, 심리적 안녕감, 삶의 질, 자아존중, 자아만족, 자기효능, 생활만족 등 의 포괄적인 의미를 내포하고 있다고 하였다.

자기만족도와 패션 및 명품관련 선행연구를 살펴 보면, Rhee(1993)는 의류제품이 갖는 내재적 요인들 이 소비자들에게 즐거움을 느끼게 할 뿐만 아니라, 의 복착용을 통해 만족감, 흥분감, 환상 등 다양한 감정 도 경험하게 한다고 하였다. 이들은 의류제품의 소비 는 제품을 통해 변화를 추구하며, 자신의 감정, 개인 의 취향, 미적인 감각뿐 아니라, 자신의 사회적인 지 위, 그리고 동조까지 표출하게 한다고 하였다. Lee and $\operatorname{Shin}(2001)$ 은 변화된 자신의 이미지에 대해 긍정적인 인식은 매력적인 외모를 지니고자 하는 기대와 자기 존중감을 향상시키고 부정적인 정서를 감소시키는 것에 의복, 액세서리 착용 등의 패션을 통한 외모의 개선이 영향을 미쳤다고 하였다. Lee et al.(2004)의 패션 명품에 대한 의식 및 구매 태도에 대한 연구에 서 명품을 구매하는 가장 큰 이유로 자기과시, 자기만 
족, 브랜드 이미지를 들었다. Sung, Lee, Shin, and Jung(2004)의 연구에서 소비자들이 명품을 소비할 때 제품의 가격과 품질을 고려하기보다 정서적이고 심 리적인 만족감을 위해 비합리적인 소비행동을 보여 주며, 과시, 동조, 사회적 안정감 등은 일반적인 상품 구매에서 얻는 가치와는 다르다고 하였다. Choo and $\operatorname{Park}(2013)$ 의 연구에서 패션연출자신감의 요인으로 정보획득, 구매결정 자신감, 타인의 평가, 상표식별능 력 자신감, 설득지식에 대한 자신감으로 분류하고, 분 석한 결과, 정보획득, 타인의 평가, 상표식별능력은 패 션연출 자신감에 긍정적인 영향을 미쳤으나 구매자 신감과 설득지식은 패션연출 자신감에 영향을 미치 지 않는 것으로 나타났다. 또한 패션연출 자신감은 중고패션제품 태도에도 긍정적인 영향을 미치는 것 으로 나타났다.

\section{Research Methods}

\section{Research questions}

본 연구는 다음과 같은 연구문제를 설정하였다.

연구문제 1. 명품쇼핑성향, 명품구매행동, 자기만 족도의 구성요인을 살펴본다.

연구문제 2. 명품쇼핑성향, 명품구매행동, 자기만 족도 요인의 연령별 차이를 알아본다.

연구문제 3. 연령에 따른 명품쇼핑성향이 자기만족 도에 미치는 영향에 대해 살펴본다.

연구문제 4. 연령에 따른 명품구매행동이 자기만족 도에 미치는 영향에 대해 살펴본다.

\section{Research methods and measurement}

연구방법은 실증적 연구를 위하여 설문지법을 이 용하였으며 선정된 문항은 명품쇼핑성향 선행연구 (Kim, 2009; Lim, 2015; Park, 2012; Park \& Hahn, 2006; Zhao, 2015)에서 26문항, 명품구매행동 선행연 구(Choi, 2010; Kim, 2011; Lee, 2010; Whang, Yoo, \& Chon, 2013; Yoon, 2013)에서 17문항, 자기만족도 선행연구(An, 2006; Ju, Bae, Choi, \& Park, 2015; Jun, 2015; Kim, 2010; Kim, 2015; Lee et al., 2009; Park, 2012)에서 16문항으로 구성하였고, 선행연구에 서 사용한 설문지 문항을 재인용하거나 연구자가 수
정 및 보완하여 본 연구에 가장 적합한 문항으로 선 정하였다. 문항의 평가는 '매우 그렇다'를 5점, '전혀 그렇지 않다’를 1점으로 하여 5단계 Likert 척도를 사 용하여 측정하였다.

\section{Data collection and analysis}

본 연구는 2016년 5월 2일부터 5월 30일까지 부산 광역시에 거주하는 20 50대의 명품 구매 경험이 있 는 여성소비자를 대상으로 부산시에 있는 롯데백화 점과 신세계백화점에서 출구조사를 통해 진행하였으 며 응답자 선정은 편의표본 추출법을 이용하였다. 연 구대상자의 수를 비슷한 수준으로 맞추기 위해 각 연 령대별로 175 부씩 총 700 부의 설문지를 배포하였고, 회수된 설문지중 불성실하게 응답한 설문지 63 부를 제 외한 최종자료는 20 대 152부, 30대 162부, 40 대 165 부, 50 대 158 부로 총 637 부를 분석에 사용하였다. 연 구대상의 연령, 직업, 수입의 특성을 알아보기 위해서 교차분석한 결과는 〈Table 1〉과 같다. 연령대가 높아 질수록 직장인의 비율은 줄어들고 개인 소득이 증가 하였으며 가족의 총수입도 증가하는 경향이 있는 것 으로 나타났다. 연령별 직업의 종류를 살펴보면 20 대 와 30 대가 직장인의 비율이 가장 높았던 반면, 40 대와 50 대는 자영업과 서비스직의 비율이 상대적으로 높은 경향을 보이고 있다. 연령별 개인 수입은 20 대와 30 대 에서 100 200만원 또는 200 300만원의 비율이 가장 높았고, 40 대와 50 대는 400 만원 이상의 비율이 가장 높게 나타났다. 가족의 월별 총 수입은 20 대와 30 대 에서 고른 분포를 보인 반면, 40 대와 50 대는 800 만원 이상의 비율이 가장 높게 나타났다. 또한 위의 차이 들은 통계적으로도 의미 있는 차이로 나타났다. 연구 자료 분석은 SPSS 21.0 통계 프로그램을 사용하였고, 분석방법으로는 교차분석, 요인분석, 신뢰도분석, 일 원배치 분산분석, Pearson 상관관계분석, 다중회귀분 석 등이 사용되었다. 분석에 사용된 각 요인은 변수 군들의 평균값을 계산하여 분석에 이용하였다.

\section{N. Result and Discussion}

1. Factor analysis of shopping tendency, purchase behavior and self-satisfaction for luxury goods

명품소비자의 쇼핑성향, 구매행동, 자기만족도의 구 
<Table 1> Demographic features of respondents

\begin{tabular}{|c|c|c|c|c|c|c|c|c|c|c|}
\hline \multirow{2}{*}{ Feature } & \multirow{2}{*}{ Answer } & \multicolumn{2}{|c|}{$20 \mathrm{~s}(n=152)$} & \multicolumn{2}{|c|}{$30 \mathrm{~s} \quad(n=162)$} & \multicolumn{2}{|c|}{$40 \mathrm{~s} \quad(n=165)$} & \multicolumn{2}{|c|}{$50 \mathrm{~s} \quad(n=158)$} & \multirow{2}{*}{$\chi^{2}$} \\
\hline & & Frequency & $\%$ & Frequency & $\%$ & Frequency & $\%$ & Frequency & $\%$ & \\
\hline \multirow{8}{*}{ Job } & Student & 32 & 21.1 & - & - & - & - & - & - & \multirow{8}{*}{$212.54^{* * *}$} \\
\hline & Workers & 86 & 56.6 & 101 & 63.1 & 62 & 38.0 & 45 & 28.7 & \\
\hline & Professionals & 11 & 7.2 & 27 & 16.9 & 28 & 17.2 & 20 & 12.7 & \\
\hline & Self-employed & 6 & 3.9 & 6 & 3.8 & 32 & 19.6 & 35 & 22.3 & \\
\hline & Service industry workers & 6 & 3.9 & 11 & 6.9 & 8 & 4.9 & 20 & 12.7 & \\
\hline & Housewives & 2 & 1.3 & 12 & 7.5 & 25 & 15.3 & 30 & 19.1 & \\
\hline & Others & 9 & 5.9 & 3 & 1.9 & 8 & 4.9 & 7 & 4.5 & \\
\hline & Total & 152 & 100.0 & 160 & 100.0 & 163 & 100.0 & 157 & 100.0 & \\
\hline \multirow{6}{*}{$\begin{array}{l}\text { Personal } \\
\text { income }\end{array}$} & Below 1 million KRW & 28 & 18.4 & 5 & 3.1 & 12 & 7.3 & 11 & 7.0 & \multirow{6}{*}{$129.94^{* * *}$} \\
\hline & 1 million 2 million $\mathrm{KRW}$ & 77 & 50.7 & 49 & 30.2 & 44 & 26.7 & 34 & 21.5 & \\
\hline & 2 million $\sim 3$ million $\mathrm{KRW}$ & 38 & 25.0 & 58 & 35.8 & 36 & 21.8 & 31 & 19.6 & \\
\hline & 3 million $\sim 4$ million $\mathrm{KRW}$ & 6 & 3.9 & 32 & 19.8 & 28 & 17.0 & 25 & 15.8 & \\
\hline & Over 4 million KRW & 3 & 2.0 & 18 & 11.1 & 45 & 27.3 & 57 & 36.1 & \\
\hline & Total & 152 & 100.0 & 162 & 100.0 & 165 & 100.0 & 158 & 100.0 & \\
\hline \multirow{6}{*}{$\begin{array}{l}\text { Household } \\
\text { income }\end{array}$} & Below 2 million KRW & 6 & 4.1 & 7 & 4.3 & 2 & 1.2 & 5 & 3.2 & \multirow{6}{*}{$22.12^{*}$} \\
\hline & 2 million $\sim 4$ million $\mathrm{KRW}$ & 21 & 14.4 & 40 & 24.7 & 25 & 15.2 & 18 & 11.4 & \\
\hline & 4 million $\sim 6$ million $\mathrm{KRW}$ & 35 & 24.0 & 38 & 23.5 & 49 & 29.9 & 43 & 27.2 & \\
\hline & 6 million $\sim 8$ million $\mathrm{KRW}$ & 43 & 29.5 & 41 & 25.3 & 34 & 20.7 & 37 & 23.4 & \\
\hline & Over 8 million KRW & 41 & 28.1 & 36 & 22.2 & 54 & 32.9 & 55 & 34.8 & \\
\hline & Total & 146 & 100.0 & 162 & 100.0 & 164 & 100.0 & 158 & 100.0 & \\
\hline
\end{tabular}

${ }^{*} p<.05, \quad{ }^{* *} p<.01,{ }^{* * *} p<.001$

성요인을 알아보기 위해 요인분석을 실시하였다. 요인분 석방법은 Varimax Rotation에 의한 요인 분석을 실시한 후 고유치 1 이상을 기준으로 요인을 추출하였고 요인별 신뢰도 검증을 실시한 결과는 〈Table $2,3,4$ )와 같다.

\section{1) Factor analysis result of luxury goods shopping} tendency

명품쇼핑성향의 요인분석에는 총 26 문항이 사용되 었다. 요인 1은 과시추구성향, 요인 2는 개성추구성향, 요인 3은 유행추구성향, 요인 4는 쾌락추구성향, 요인 5 는 합리적 성향으로 명명하였다. 상기 요인의 전체분 산 설명력은 $63.67 \%$ 였으며, 문항의 신뢰도는 .89 에서
.74 까지의 분포로 나타났다(Table 2).

\section{2) Factor analysis result of luxury goods purchase behavior}

명품구매행동의 요인분석에는 총 17 문항이 사용되 었다. 요인 1은 고급지향형, 요인 2는 동조지향형, 요 인 3은 실용지향형으로 명명하였다. 상기 요인의 전 체분산 설명력은 $57.13 \%$ 였으며, 문항의 신뢰도는 .85 에서 .79까지의 분포로 나타났다(Table 3).

\section{3) Factor analysis result of self-satisfaction} 자기만족도의 요인분석에는 총 16 문항이 사용되었 
<Table 2> Factor analysis result of luxury goods shopping tendency

\begin{tabular}{|c|c|c|c|c|c|}
\hline Factor & Question & $\begin{array}{l}\text { Factor } \\
\text { score }\end{array}$ & $\begin{array}{l}\text { Eigen } \\
\text { value }\end{array}$ & $\begin{array}{l}\text { Cumulative } \\
\qquad \%)\end{array}$ & $\begin{array}{c}\text { Cronbach's } \\
\alpha\end{array}$ \\
\hline \multirow{6}{*}{$\begin{array}{l}\text { Show-off } \\
\text { pursuit } \\
\text { tendency }\end{array}$} & $\begin{array}{l}\text { If the price is the same, I would like to buy foreign } \\
\text { brand products than domestic products. }\end{array}$ & .65 & \multirow{6}{*}{9.21} & \multirow{6}{*}{35.44} & \multirow{6}{*}{.85} \\
\hline & $\begin{array}{l}\text { Sometimes, I purchase expensive brand products beyond } \\
\text { my economic ability. }\end{array}$ & .46 & & & \\
\hline & $\begin{array}{l}\text { Famous brand products are the symbol of social success } \\
\text { and position. }\end{array}$ & .73 & & & \\
\hline & In spite of high price, I like famous brand products. & .68 & & & \\
\hline & $\begin{array}{l}\text { I consider whether it is the famous brand which others } \\
\text { know. }\end{array}$ & .70 & & & \\
\hline & $\begin{array}{l}\text { I make much of brand products indicating the level of } \\
\text { my wealth. }\end{array}$ & .65 & & & \\
\hline \multirow{5}{*}{$\begin{array}{c}\text { Individuality } \\
\text { pursuit } \\
\text { tendency }\end{array}$} & I want to emphasize individuality by rare brand products. & .67 & \multirow{5}{*}{2.48} & \multirow{5}{*}{44.99} & \multirow{5}{*}{.87} \\
\hline & I like unique brand products drawing others' attention. & .62 & & & \\
\hline & I like brand products which can create my unique image. & .85 & & & \\
\hline & I like brand products which express my individuality. & .85 & & & \\
\hline & I prefer the differentiated brand design. & .76 & & & \\
\hline \multirow{5}{*}{$\begin{array}{c}\text { Trend } \\
\text { pursuit } \\
\text { tendency }\end{array}$} & I like the popular brand products. & .67 & \multirow{5}{*}{2.10} & \multirow{5}{*}{53.06} & \multirow{5}{*}{.89} \\
\hline & $\begin{array}{l}\text { I feel pleasant somehow when I put on the popular brand } \\
\text { products. }\end{array}$ & .75 & & & \\
\hline & $\begin{array}{l}\text { I want to have the brand product of new style when it is } \\
\text { the trendy item. }\end{array}$ & .77 & & & \\
\hline & I want to buy brand products which celebrities have. & .76 & & & \\
\hline & I want to buy popular brand products before others do. & .69 & & & \\
\hline \multirow{5}{*}{$\begin{array}{l}\text { Pleasure } \\
\text { pursuit } \\
\text { tendency }\end{array}$} & I like shopping as looking around several brand shops. & .55 & \multirow{5}{*}{1.65} & \multirow{5}{*}{59.39} & \multirow{5}{*}{.87} \\
\hline & $\begin{array}{l}\text { I do shopping for refreshing myself not because I need } \\
\text { something. }\end{array}$ & .68 & & & \\
\hline & I do shopping in most cases when I have time. & .83 & & & \\
\hline & It's more exciting to spend time for shopping than others. & .85 & & & \\
\hline & It's the pleasure for me to do shopping in any places. & .83 & & & \\
\hline \multirow{5}{*}{$\begin{array}{l}\text { Rational } \\
\text { shopping } \\
\text { tendency }\end{array}$} & I tend to buy brad products suitable for my economic ability. & .57 & \multirow{5}{*}{1.11} & \multirow{5}{*}{63.67} & \multirow{5}{*}{.74} \\
\hline & I tend to buy mainly during the season for bargan sales. & 69 & & & \\
\hline & I plan before buying brand products. & .78 & & & \\
\hline & I invest time for buying quality brand products. & .66 & & & \\
\hline & $\begin{array}{l}\text { I buy when a brand product I want to buy is the best } \\
\text { quality product among the similar price items. }\end{array}$ & .61 & & & \\
\hline
\end{tabular}


$<$ Table 3> Factor analysis result of luxury goods purchase behavior

\begin{tabular}{|c|c|c|c|c|c|}
\hline Factor & Question & $\begin{array}{c}\text { Factor } \\
\text { score }\end{array}$ & $\begin{array}{l}\text { Eigen } \\
\text { value }\end{array}$ & $\begin{array}{l}\text { Cumulative } \\
(\%)\end{array}$ & $\begin{array}{c}\text { Cronbach's } \\
\alpha\end{array}$ \\
\hline \multirow{6}{*}{$\begin{array}{l}\text { High } \\
\text { quality }\end{array}$} & I buy the brand products from famous brand shops. & .71 & \multirow{6}{*}{6.07} & \multirow{6}{*}{35.73} & \multirow{6}{*}{.83} \\
\hline & I buy the best quality brand products. & .63 & & & \\
\hline & $\begin{array}{l}\text { I buy the brand product looking dignified as compared to } \\
\text { the price. }\end{array}$ & .72 & & & \\
\hline & $\begin{array}{l}\text { I buy brand products because they are valuable enough to } \\
\text { compensate the high price. }\end{array}$ & .79 & & & \\
\hline & $\begin{array}{l}\text { I buy the brand products with the distinguished design } \\
\text { and quality without thinking about prices. }\end{array}$ & .59 & & & \\
\hline & $\begin{array}{l}\text { I buy quality brand products because of their history and } \\
\text { tradition. }\end{array}$ & .54 & & & \\
\hline \multirow{5}{*}{ Conformity } & I buy brand products to draw attention from others. & .79 & \multirow{5}{*}{2.27} & \multirow{5}{*}{49.05} & \multirow{5}{*}{.85} \\
\hline & $\begin{array}{l}\text { I buy the brand products similar to those which my } \\
\text { acquaintance has. }\end{array}$ & .69 & & & \\
\hline & $\begin{array}{l}\text { I buy the brand products even though I have no economic } \\
\text { ability enough to buy them. }\end{array}$ & .76 & & & \\
\hline & I buy the widely known brand products. & .57 & & & \\
\hline & I buy the brand products in popular design. & .61 & & & \\
\hline \multirow{6}{*}{ Practicality } & I plan the budget for buying the brand products. & .46 & \multirow{6}{*}{1.37} & \multirow{6}{*}{57.13} & \multirow{6}{*}{.79} \\
\hline & $\begin{array}{l}\text { I buy the brand products mainly during the season for } \\
\text { bargain sales. }\end{array}$ & .79 & & & \\
\hline & I buy the brand products mainly in duty free shops. & .71 & & & \\
\hline & I buy the brand products mainly in wholesale stores. & .77 & & & \\
\hline & I buy the brand products mainly in online markets. & .54 & & & \\
\hline & $\begin{array}{l}\text { I buy the brand products mainly when there is any benefit } \\
\text { such as points or free gifts. }\end{array}$ & .74 & & & \\
\hline
\end{tabular}

다. 요인 1은 자아만족, 요인 2는 대인만족, 요인 3은 경제만족으로 명명하였다. 상기 요인의 전체분산 설 명력은 $57.42 \%$ 였으며, 문항의 신뢰도는 .89에서 .81 까지의 분포로 나타났다(Table 4).

\section{Difference of luxury goods shopping tendency,} luxury goods purchase behavior and self-satisfaction by ages group

연령별 명품쇼핑성향, 명품구매행동, 자기만족도 요인의 차이를 알아보기 위하여 일원배치 분산분석과 Duncan's multiple range test를 실시한 결과는 〈Table $5>$ 와 같다.

연령별 명품쇼핑성향, 명품구매행동, 자기만족도의 차이를 알아본 결과 명품쇼핑성향의 쾌락추구성향
요인과 자기만족도의 대인만족 요인에서만 연령별 유의한 차이가 나타났다. 명품쇼핑성향은 대체로 모 든 요인에서 평균정도의 수치를 나타냈으며, 쾌락추 구성향은 40 50대보다 20 30대에서 비교적 높은 수 치로 나타나, 즐거움을 위해 명품을 구매하는 경향은 20 30대가 더 큰 것으로 볼 수 있다. 이러한 결과는 Jung(2007)의 연구에서 젊은 층의 소비자들일수록 쇼 핑을 즐기며, 명품을 선호하고, 신제품이 나오면 신속 히 구매한다고 한 연구의 결과와 유사하였다. 명품구 매행동에서는 전체적으로 연령별 차이가 나타나지 않 았으나, Shin and $\mathrm{Na}(2003)$ 의 연구에서는 명품을 구 매 시 연령별로 차이를 보인다고 하여 본 연구의 결 과와는 다르게 나타났다. 본 연구에서 연령별 차이가 없는 이유로는 명품이 일반제품과 구별하게 만드는 명 
$<$ Table 4> Factor analysis result of self-satisfaction

\begin{tabular}{|c|c|c|c|c|c|}
\hline Factor & Question & $\begin{array}{c}\text { Factor } \\
\text { score }\end{array}$ & $\begin{array}{l}\text { Eigen } \\
\text { value }\end{array}$ & $\begin{array}{c}\text { Cumulative } \\
(\%)\end{array}$ & $\begin{array}{c}\text { Cronbach's } \\
\alpha\end{array}$ \\
\hline \multirow{10}{*}{$\begin{array}{c}\text { Self- } \\
\text { contentment }\end{array}$} & I think my life is generally successful. & .62 & \multirow{10}{*}{8.05} & \multirow{10}{*}{40.26} & \multirow{10}{*}{.82} \\
\hline & I think I have good personality. & .55 & & & \\
\hline & I feel pride on what I do. & .71 & & & \\
\hline & I am satisfied with the current life style. & .62 & & & \\
\hline & I am satisfied because I can try a variety of new things. & .65 & & & \\
\hline & I like looking into a mirror. & .37 & & & \\
\hline & I have positive attitutde on myself. & .64 & & & \\
\hline & I am generally satisfied with myself. & .62 & & & \\
\hline & I think I am valuable. & .64 & & & \\
\hline & I am proud of myself. & .67 & & & \\
\hline \multirow{5}{*}{$\begin{array}{l}\text { Interpersonal } \\
\text { satisfaction }\end{array}$} & I have exciting and interesting life with people around me. & .61 & \multirow{5}{*}{2.09} & \multirow{5}{*}{50.70} & \multirow{5}{*}{.89} \\
\hline & I tend to respect others' opinions. & .72 & & & \\
\hline & I have happy life with my family. & .68 & & & \\
\hline & I am satisfied with doing something with others. & .67 & & & \\
\hline & I have good relationship with others. & .77 & & & \\
\hline \multirow{5}{*}{$\begin{array}{l}\text { Economic } \\
\text { satisfaction }\end{array}$} & I am satisfied with current income. & .80 & \multirow{5}{*}{1.35} & \multirow{5}{*}{57.42} & \multirow{5}{*}{.81} \\
\hline & I am satisfied with the living expenditure. & .80 & & & \\
\hline & I am economically rich. & .83 & & & \\
\hline & I have very good living environment. & .77 & & & \\
\hline & My life is very stable. & .75 & & & \\
\hline
\end{tabular}

<Table 5> Difference of luxury goods shopping tendency, luxury goods purchase behavior and self-satisfaction by ages group

\begin{tabular}{|c|c|c|c|c|c|c|}
\hline \multirow[b]{2}{*}{ Group } & \multirow[b]{2}{*}{ Factor } & \multicolumn{4}{|c|}{ Age Group } & \multirow[b]{2}{*}{$F$-value } \\
\hline & & $\begin{array}{c}20 \mathrm{~s} \\
\mathrm{M}(\mathrm{SD})\end{array}$ & $\begin{array}{c}30 \mathrm{~s} \\
\mathrm{M}(\mathrm{SD})\end{array}$ & $\begin{array}{c}40 \mathrm{~s} \\
\mathrm{M}(\mathrm{SD})\end{array}$ & $\begin{array}{c}50 \mathrm{~s} \\
\mathrm{M}(\mathrm{SD})\end{array}$ & \\
\hline \multirow{5}{*}{$\begin{array}{c}\text { Luxury goods } \\
\text { shopping } \\
\text { tendency }\end{array}$} & Show-off pursuit tendency & $2.71(.72)$ & $2.89(.75)$ & $2.85(.78)$ & $2.85(.86)$ & 1.58 \\
\hline & Individuality pursuit tendency & $2.96(.81)$ & $3.10(.85)$ & $3.13(.93)$ & $3.17(.87)$ & 1.75 \\
\hline & Trend pursuit tendency & $2.70(.88)$ & $2.90(.87)$ & $2.76(.92)$ & $2.84(.98)$ & 1.46 \\
\hline & Pleasure pursuit tendency & 3.13(.77)A & $3.10(.85) \mathrm{A}$ & $2.86(.90) \mathrm{B}$ & $2.99(.92) \mathrm{AB}$ & $3.10^{*}$ \\
\hline & Rational shopping tendency & $3.25(.67)$ & $3.23(.64)$ & $3.25(.72)$ & $3.21(.81)$ & .14 \\
\hline \multirow{3}{*}{$\begin{array}{c}\text { Luxury goods } \\
\text { purchase } \\
\text { behavior }\end{array}$} & High quality & $3.48(.54)$ & $3.49(.51)$ & $3.49(.64)$ & $3.42(.62)$ & .56 \\
\hline & Conformity & $3.81(.54)$ & $3.70(.50)$ & $3.74(.53)$ & $3.68(.59)$ & 1.66 \\
\hline & Practicality & $2.94(.64)$ & $3.08(.62)$ & $3.13(.78)$ & $3.11(.74)$ & 2.25 \\
\hline \multirow{3}{*}{$\begin{array}{c}\text { Self- } \\
\text { satisfaction }\end{array}$} & Self-contentment & $2.96(.72)$ & $3.08(.72)$ & $3.08(.78)$ & $3.08(.86)$ & .98 \\
\hline & Interpersonal satisfaction & $2.45(.62) \mathrm{B}$ & $2.63(.71) \mathrm{A}$ & $2.62(.72) \mathrm{A}$ & $2.69(.82) \mathrm{A}$ & $3.06^{*}$ \\
\hline & Economic satisfaction & $2.76(.73)$ & $2.75(.65)$ & $2.83(.74)$ & $2.78(.74)$ & .38 \\
\hline
\end{tabular}

${ }^{*} p<.05,{ }^{* *} p<.01,{ }^{* * *} p<.001$, Duncan's multiple range test: $\mathrm{A}>\mathrm{B}>\mathrm{C}>\mathrm{D}$ 
품의 속성, 즉 명품성이 제공하는 상황적 혜택이 소 비자의 심리적 만족에 영향을 미치는 중요한 요인이 라고 한 $\operatorname{Lim}(2015)$ 의 연구로 설명된다. 즉, 명품이 가 진 브랜드의 가치, 전통성, 디자인, 고급성, 내구성 등 의 특성으로 인해 나이가 들어도 질리지 않고, 유행 과 상관없이 오래도록 사용 가능하며, 고급스러움으 로 자신의 사회적 능력을 과시할 수 있는 상황적인 혜 택에 만족한다는 소비자 심리에 따라 명품은 연령에 관계없이 선호될 수 있으므로 연령별 차이가 나타나 지 않은 것으로 생각된다. 자기만족도에서는 대인만 족에서 연령별 차이가 나타났는데, 대체로 평균 이하 의 수치로 나타났으며, 20대보다 30 50대에서 비교 적 높은 수치로 나타났다. 이는 주변사람들과의 대인 관계에서 20대보다는 30 50대가 명품을 소유하였을 때 더욱 만족하는 것으로 볼 수 있다. 그러나 Choi (2001)의 연구에서는 20 50대까지의 여성을 대상으로 명품에 대한 태도를 알아본 결과, 20 대가 다른 연령
대보다 패션명품에 대한 관심과 품질을 높게 인식하 고, 명품에 대해 매우 호의적인 것으로 밝혀진 것과 는 차이가 있었다.

\section{Impact of luxury goods shopping tendency on} self-satisfaction by age group

연령별 명품쇼핑성향이 자기만족도에 미치는 영향 을 분석한 결과는〈Table 6〉과 같다.

연령별 명품쇼핑성향이 자아만족에 미치는 영향을 분석한 결과, 20 대에서는 개성추구성향과 합리적 성 향이 자아만족에 정적인 영향을 미치는 것으로 나타 났으며, 30대에서는 쾌락추구성향과 합리적 성향이 자아만족에 정적인 영향을 미치는 것으로 나타났다. 40대에서는 쾌락추구성향이 자아만족에 정적인 영향 을 미치는 것으로 나타났으며, 50대에서는 쾌락추구 성향과 합리적 성향이 자아만족에 정적인 영향을 미 치는 것으로 나타났다. 연령별 명품쇼핑성향이 대인

<Table 6> Analysis on the impact of luxury goods shopping tendency on self-satisfaction by age group

\begin{tabular}{|c|c|c|c|c|c|c|c|c|c|c|c|c|}
\hline \multirow{3}{*}{$\begin{array}{l}\text { Luxury } \\
\text { goods } \\
\text { shopping } \\
\text { tendency } \\
(\beta)\end{array}$} & \multicolumn{12}{|c|}{ Self-satisfaction } \\
\hline & \multicolumn{4}{|c|}{ Self-contentment } & \multicolumn{4}{|c|}{ Interpersonal satisfaction } & \multicolumn{4}{|c|}{ Economic satisfaction } \\
\hline & $\begin{array}{c}20 \\
(n=152)\end{array}$ & $\begin{array}{c}30 \\
(n=162)\end{array}$ & $\begin{array}{c}40 \\
(n=165)\end{array}$ & $\begin{array}{c}50 \\
(n=158)\end{array}$ & $\begin{array}{c}20 \\
(n=152)\end{array}$ & $\begin{array}{c}30 \\
(n=162)\end{array}$ & $\begin{array}{c}40 \\
n=165)\end{array}$ & $\begin{array}{c}50 \\
(n=158)\end{array}$ & $\begin{array}{c}20 \\
(n=152)\end{array}$ & $\begin{array}{c}30 \\
(n=162)\end{array}$ & $\begin{array}{c}40 \\
(n=165)\end{array}$ & $\begin{array}{c}50 \\
(n=158)\end{array}$ \\
\hline $\begin{array}{l}\text { Show-off } \\
\text { pursuit } \\
\text { tendency }\end{array}$ & -.07 & -.09 & .02 & .08 & .01 & $-.23^{*}$ & -.06 & -.03 & .02 & -.10 & .05 & .24 \\
\hline $\begin{array}{c}\text { Individuality } \\
\text { pursuit } \\
\text { tendency }\end{array}$ & $.23^{* *}$ & -.09 & -.06 & .18 & .08 & -.03 & -.07 & .13 & .01 & -.00 & -.12 & -.10 \\
\hline $\begin{array}{c}\text { Trend } \\
\text { pursuit } \\
\text { tendency }\end{array}$ & .00 & .00 & -.08 & -.06 & .00 & .13 & -.03 & -.16 & .08 & .07 & .01 & -.06 \\
\hline $\begin{array}{l}\text { Pleasure } \\
\text { pursuit } \\
\text { tendency }\end{array}$ & .13 & $.28^{* *}$ & $.24^{*}$ & $.20^{*}$ & .17 & $.22^{*}$ & .18 & $.24^{*}$ & -.03 & $.20^{*}$ & $.33^{* *}$ & .11 \\
\hline $\begin{array}{l}\text { Rational } \\
\text { shopping } \\
\text { tendency }\end{array}$ & $.22^{* *}$ & $.27^{* *}$ & .07 & $.17^{*}$ & $.18^{*}$ & $.24^{* *}$ & $.28^{* *}$ & $.18^{*}$ & .16 & .12 & -.01 & .10 \\
\hline$R^{2}$ & .10 & .11 & .02 & .15 & .05 & .09 & .08 & .09 & .00 & .04 & .07 & .04 \\
\hline$F$ & $4.45^{* *}$ & $4.99^{* * *}$ & 1.55 & $6.36^{* * *}$ & $2.65^{*}$ & $4.31^{* *}$ & $3.75^{* *}$ & $3.92^{* *}$ & 1.09 & 2.22 & $3.33^{* *}$ & 2.22 \\
\hline
\end{tabular}


만족에 미치는 영향을 분석한 결과 20대에서는 합리 적 성향이 대인만족에 정적인 영향을 미치는 것으로 나타났다. 30 대에서는 쾌락추구성향과 합리적 성향이 대인만족에 정적인 영향을 미쳤고, 과시추구성향은 대인만족에 부적인 영향을 미치는 것으로 나타났다. 40 대에서는 합리적 성향이 대인만족에 정적인 영향을 미치는 것으로 나타났고, 50 대에서는 쾌락추구성향과 합리적 성향이 대인만족에 정적인 영향을 미치는 것 으로 나타났다. 연령별 명품쇼핑성향이 경제만족에 미치는 영향을 분석한 결과 20 대에서는 경제만족에 영향을 미치는 요인이 없는 것으로 나타났다. 30 40 대에서는 쾌락추구성향이 경제만족에 정적인 영향을 미치는 것으로 나타났다. 50 대에서는 경제만족에 영 향을 미치는 요인이 없는 것으로 나타났다. $\operatorname{Jin}(2014)$ 은 20 30대를 대상으로 연구하였는데 대부분이 학생 이거나 사회초년생으로 한정된 수입이나 경제적 부담 감으로 인하여 소비에 대한 욕구를 억제하는 것으로 나타났고, Park(2012)의 연구에서는 명품브랜드사용 자 성향과의 관계를 알아보았는데, 전반적으로 자기 만족을 위해 명품구매에서 쾌락적 즐거움을 찾는 것 으로 나타나 본 연구의 결과와 유사하였다.

\section{Impact of luxury goods purchase behavior on} self-satisfaction by age group

연령별 명품구매행동이 자기만족도에 미치는 영향 을 분석한 결과는 〈Table 7〉과 같다.
연령별 명품구매행동이 자아만족에 미치는 영향을 분석한 결과 20 대와 50 대는 고급지향형이 자아만족 에 정적인 영향을 미치는 것으로 나타났다. 30 대에서 는 고급지향형이 자아만족에 정적인 영향을, 동조지 향형은 자아만족에 부적인 영향을 미치는 것으로 나 타났다. 40 대에서는 자아만족에 영향을 미치는 요인 이 없는 것으로 나타났다. 연령별 명품구매행동이 대 인만족에 미치는 영향을 분석한 결과 20 대에서는 실 용지향형이 대인만족에 정적인 영향을 미치는 것으 로 나타났다. 30 대에서는 고급지향형이 대인만족에 정적인 영향을, 동조지향형은 대인만족에 부적인 영 향을 미치는 것으로 나타났다. 40 50대에서는 고급지 향형이 대인만족에 정적인 영향을 미치는 것으로 나 타났다. 연령별 명품구매행동이 경제만족에 미치는 영향을 분석한 결과, 20 대에서는 고급지향형이 경제 만족에 정적인 영향을 미치는 것으로 나타났다. 30 대 와 40 대에서는 경제만족에 정적인 영향을 미치는 요 인이 없는 것으로 나타났다. 50대에서는 고급지향형 이 경제만족에 정적인 영향을, 실용지향형은 경제만 족에 부적인 영향을 미치는 것으로 나타났다. 따라서 연령이 낮을수록 명품을 더 선호하는 경향을 띄고, 상위직 여성, 소비생활수준, 학력, 사회적 지위, 연령, 수입이 명품 구매빈도에 영향력을 가진다고 한 Chae and Rhee(2005)의 연구 결과는 연령층이 높아짐에 따 라 자기만족이 다르게 나타난 본 연구의 결과를 설명 하는데 뒷받침될 수 있다.

<Table 7> Analysis on the impact of luxury goods purchase behavior on self-satisfaction by age group

\begin{tabular}{|c|c|c|c|c|c|c|c|c|c|c|c|c|}
\hline \multirow{3}{*}{$\begin{array}{l}\text { Luxury } \\
\text { goods } \\
\text { purchase } \\
\text { behavior } \\
\quad(\beta)\end{array}$} & \multicolumn{12}{|c|}{ Self-satisfaction } \\
\hline & \multicolumn{4}{|c|}{ Self-contentment } & \multicolumn{4}{|c|}{ Interpersonal satisfaction } & \multicolumn{4}{|c|}{ Economic satisfaction } \\
\hline & $\begin{array}{c}20 \\
(n=152)\end{array}$ & $\begin{array}{c}30 \\
(n=162)\end{array}$ & $\begin{array}{c}40 \\
(n=165)\end{array}$ & $\begin{array}{c}50 \\
(n=158)\end{array}$ & $\begin{array}{c}20 \\
(n=152)\end{array}$ & $\begin{array}{c}30 \\
(n=162)\end{array}$ & $\begin{array}{c}40 \\
(n=165)\end{array}$ & $\begin{array}{c}50 \\
(n=158)\end{array}$ & $\begin{array}{c}20 \\
(n=152)\end{array}$ & $\begin{array}{c}30 \\
(n=162)\end{array}$ & $\begin{array}{c}40 \\
(n=165)\end{array}$ & $\begin{array}{c}50 \\
(n=158)\end{array}$ \\
\hline High quality & $.26^{*}$ & $.40^{* * *}$ & .19 & $.60^{* * *}$ & .11 & $.30^{* *}$ & $.24^{*}$ & $.44^{* * *}$ & $.21^{*}$ & .195 & .15 & $.43^{* * *}$ \\
\hline Conformity & .00 & $-.23^{*}$ & -.07 & -.16 & .03 & $-.21^{*}$ & -.12 & -.29 & .01 & -.037 & .11 & -.10 \\
\hline Practicality & .08 & .05 & .00 & -.08 & $.19^{*}$ & .03 & .10 & -.05 & .02 & .024 & -.09 & $-.26^{* *}$ \\
\hline$R^{2}$ & .07 & .08 & .00 & .21 & .05 & .04 & .03 & .07 & .03 & .014 & .03 & .13 \\
\hline$F$ & $4.70^{*}$ & $5.70^{* *}$ & 1.21 & $14.78^{* * *}$ & $3.82^{*}$ & $3.02^{*}$ & $2.72^{*}$ & $4.84^{* *}$ & 2.63 & 1.76 & 2.72 & $8.36^{* * *}$ \\
\hline
\end{tabular}

${ }^{*} p<.05, \quad{ }^{* *} p<.01, \quad{ }^{* * *} p<.001$ 


\section{Conclusion}

명품 소비자의 쇼핑성향, 구매행동, 자기만족도의 차이를 연령별로 살펴보고, 명품쇼핑성향과 명품구매 행동이 자기만족도에 미치는 영향을 알아본 결과는 다음과 같다.

첫째, 명품쇼핑성향, 명품구매행동, 자기만족도의 구성요인을 분석한 결과, 명품쇼핑성향의 하위요인 은 과시추구성향, 개성추구성향, 유행추구성향, 쾌락 추구성향, 합리적 성향으로 구성되었다. 명품구매행 동의 하위요인은 고급지향형, 동조지향형, 실용지향 형으로 구성되었고, 자기만족도의 하위요인은 자아 만족, 경제만족, 대인만족으로 구성되었다.

둘째, 연령에 따른 명품쇼핑성향, 명품구매행동, 자 기만족도의 차이를 분석한 결과 명품쇼핑성향 중 쾌 락추구성향에서 40 50대보다 20 30대에서 높게 나타 나 연령별 차이를 보였다. 결과를 볼 때 대중화되어 가 고 있는 국내 명품 시장에서 명품을 쇼핑하는 20 30 대와 40 50대의 소비자의 감성은 다를 것으로 예상 되며, 특히 20 30대 여성들이 향후 높은 경제력을 갖 게 되었을 때 명품을 재구매할 가능성 있는 잠재적 소비자로 인식된다고 볼 수 있다. 따라서 고연령층과 최상류층을 위한 고가의 최고급 품질의 상품전략 이 외에 젊은 고객을 위한 가격대가 낮은 세컨브랜드의 개발로 고객층 확산을 위한 패션명품기업들의 차별 화된 마케팅 전략이 요구된다. 명품구매행동에서는 연령별 차이가 나타나지 않았다. 이러한 결과는 명품 의 고급성, 소장가치, 내구성, 디자인 등의 특성으로 인해 소비자들의 연령에 관계없이 선호되고 있기 때 문인 것으로 사료되며, 연령별 소비심리를 파악하여 연령별 요구(needs)에 적합한 제품을 제안할 수 있는 마케팅 전략이 필요할 것으로 생각된다. 자기만족도 에서는 20 대보다는 $30 ~ 50$ 대에서 대인만족이 더욱 높 게 나타나, 나이가 들수록 고급성과 고가격대의 상품 이 자신의 신분이나 지위를 보여줄 수 있는 수단으로 사용되어 명품을 통해 대인관계에 더 긍정적인 자기 만족을 하는 것으로 볼 수 있다.

셋째, 연령별 쇼핑성향이 자기만족도에 미치는 영 향을 분석한 결과 20 대는 개성추구성향, 합리적 성향 이 자아만족을 주고, 합리적 성향은 대인만족을 주었 다. 즉, 다른 연령대에 비해 경제력이 높지 않은 20 대
는 명품구매 시 예산을 세우거나 시간을 투자하고, 적 은 비용으로 명품을 소유함으로써 자아만족과 대인 만족을 하는 것으로 보이며, 유행을 추구하기보다는 자신만의 개성을 표현하는 것으로 자아만족을 하는 것을 알 수 있다. 30 대는 쾌락추구성향과 합리적 성 향이 자아만족과 대인만족을 주고, 과시추구성향은 대인만족에 부적인 영향을 주고 있으며, 쾌락추구성 향은 경제만족을 주고 있다. 40 대는 쾌락추구성향이 자아만족과 경제만족을 주고, 합리적 성향이 대인만 족을 주었다. 50 대는 쾌락추구성향과 합리적 성향이 자아만족과 대인만족을 주었다. 즉, 30 50대는 사교 모임이나 대인관계가 많은 시기로 사람들과의 만남 에서 고급품의 과시에 의해 만족감을 가지고 경제적 으로 합리성이 있는 소비로서 자기만족을 하는 것으 로 볼 수 있다. 연령별 구매행동이 자기만족도에 미 치는 영향을 분석한 결과 20 대는 고급지향형이 자아 만족과 대인만족에 영향을 주고, 실용지향형은 대인 만족에 영향을 주는 것으로 나타났다. 즉, 20 대는 명 품구매 시 아울렛이나 세일기간을 활용하고, 고급스 러운 브랜드의 구매가 자기만족과 대인관계에 긍정 적 역할을 하는 것으로 보인다. 30 대는 고급지향형이 자아만족과 대인만족을 주고, 동조지향형은 자아만족 과 대인만족에 부적인 영향을 주는 것으로 나타났다. 30 대는 남들과는 다른 나만의 스타일을 추구하고, 사 회활동을 통한 경제적 만족을 이루고 있으며, 가격에 비해 고급스러운 제품을 구매하는 것이 자기만족으 로 이어졌고, 주위 사람들과 비슷한 동조성 있는 명 품구매는 자아만족과 대인만족을 주지 않는 것으로 나타났다. 40 대는 고급지향형은 대인만족을 주는 것 으로 나타나 40 대는 고급스러운 브랜드의 구매를 통 해 대인관계에 긍정적 영향을 주는 것으로 나타났다. 50 대는 고급지향형이 자아만족과 대인만족, 경제만족 을 주고, 실용지향형은 대인만족에 부적인 영향을 주 는 것으로 나타나, 50 대는 명품구매 시 예산을 세워 서 할인매장을 찾거나 세일기간 등을 고려하지는 않 지만 자기 관리에 투자할 돈과 시간적 여유가 많아진 중년여성들이 늘어나면서 자기만족을 위해 고급스러 운 명품을 구매하는 것으로 보인다. 위의 결과, 연령 별 명품 소비자의 쇼핑성향과 구매행동이 자기만족 도에 영향을 미치고 있음이 밝혀졌다. 본 연구의 결 과를 바탕으로 목표 고객에 대한 가격, 유통전략, 포 
지셔닝 전략 등 전반적인 마케팅 전략에 도움을 주는 기초자료를 제공할 수 있을 것으로 생각된다. 이러한 결과는 연령별로 소비시장 세분화에 도움을 줄 수 있 고 소비자 요구가 반영된 상품기획 및 잠재적 소비자 를 이끌어 내기 위한 마케팅 전략에 필요한 기초자료 로 도움이 되기를 기대한다.

본 연구의 대상이 부산지역에 거주하는 여성으로 한정하여 조사한 것이므로 모든 지역의 여성을 대표 하지 못하는 한계점은 연구의 결과를 일반화 하는데 다소 무리가 있으므로 후속 연구에서는 광범위한 지 역을 대상으로 직업형태, 성별, 연령 등을 확대하여 다양한 변인들을 비교 분석할 수 있는 연구가 필요할 것으로 사료된다.

\section{References}

An, S. N. (2006). The causal relationship between self-discrepancy and life satisfaction according to self-construals. Unpublished master's thesis, Yonsei University, Seoul, Korea.

Bae, J. W. (2016, November 1). "소비자 스스로 제품 을 자랑하게 만들어라" SNS 시대 마케팅 전략 ' 좋아요를 삽니다' 저자 김대영 ["Make yourself proud of your product" SNS marketing strategy 'Buy Like']. Chosun Biz, Retrieved December 21, 2016, from http://biz.chosun.com/site/data/html_dir/ 2016/11/01/2016110100600.html

Bae, J.-H. (2005). A study on influence factor about purchase behavior of luxury product: Focused on consumer value and brand function. Unpublished master's thesis, Chung-Ang University, Seoul, Korea.

Bae, S.-J. (2009). An analysis of the design characteristics of 'Vivienne Tam' collections, for the launch of renowned Korean luxury fashion brands. Journal of the Korean Society of Costume, 59(8), 82-96.

Campbell, C. (1997). Shopping, pleasure and the sex war. In P. Falk \& C. Campbell (Eds.), The shopping experience (pp. 166-176). doi:10.4135/ 9781446216972.n8
Cha, K.-H. (2001). Five factors of personality and life satisfaction among college students. The Korea Journal of Youth Counseling, 9, 7-26.

Chae, J. M., \& Rhee, E. Y. (2005). Attitude and purchase frequency toward foreign luxury goods related to age and social stratification variables. Journal of the Korean Society of Clothing and Textiles, 29(6), 885-895.

Choi, S. H. (1996). A study of general values and clothing shopping orientations for unmarried women. Unpublished master's thesis, Ewha Womans University, Seoul, Korea.

Choi, S.-H. (2001). A study on the attitude toward fashion luxury products. The Research Journal of the Costume Culture, 9(6), 843-854.

Choi, S.-Y. (2010). 20-30 in lifestyle and fashion brand purchasing behavior study. Unpublished master's thesis, Kookmin University, Seoul, Korea.

Choi, Y. J. (2010). The effect of conspicuous consumption and fashion leadership on benefit seeking and brand loyalty of luxury goods. Unpublished master's thesis, Konkuk University, Seoul, Korea.

Choo, T. G., \& Park, H. H. (2013). The effect of consumption value on attitude and repurchase intention of secondhand fashion goods: The moderating role of self-confidence in fashion coordination. Journal of the Korean Society of Clothing and Textiles, 37(4), 618-630. doi:10.5850/JKSCT.2013. 37.4.618

George. L. K., Mutran, E. J., \& Pennybacker, M. R. (1980). The meaning and measurement of age identity. Experimental Aging Research, 6(3). 283-298. doi:10.1080/ 03610738008258364

Hwang, S. J. (2016). The effects of perceived quality on customer satisfaction and recommendation in luxury purchases. Unpublished doctoral dissertation, Busan University of Foreign Studies, Busan, Korea.

Jeong, H.-D. (2000). A study on consumer shopping orientation and buying behavior according to FTA. Unpublished doctoral dissertation, Catholic University of Daegu, Gyeongsangbuk-do, Korea. 
Jin, X. M. (2014). Fashion consumption for healing. Unpublished master's thesis, Korea University, Seoul, Korea.

Ju, D.-B., Bae, H., Choi, D.-K., \& Park, J.-H. (2015). The analysis of difference in early adolescent's self-satisfaction and self-regulation in low-income area by the amount of time be alone. Korean Journal of Local Government \& Administration Studies, 29(3), 107-124.

Jun, B. S. (2015). A study on influence factors and satisfaction of self-gift consumption behavior. Unpublished master's thesis, Seoul National University, Seoul, Korea.

Jung, Y. H. (2007). A study on fashion behavior and make-up behavior in terms of the lifestyle and the self-concept of post digital generation. Unpublished doctoral dissertation, Catholic University of Daegu, Gyeongsangbuk-do, Korea.

Kalish, R. A. (1975). Late adulthood: Perspectives on human development. Monterey, CA: Brooks/Cole Publishing Company.

Kang, B.-K., \& Hwang, J.-S. (2011). The combination of product attributes in luxury fashion brands. Journal of the Korean Fashion \& Costume Design Association, 13(2), 89-101.

Kim, B. G. (1999). 소비자의 문제인식스타일과 쇼핑성 향과의 관계 [The relationship between consumer 's problem recognition style and shopping orientation]. Journal of Consumption Culture, 2(1), 1-15.

Kim, B.-S. (2006). A study on the effects of environmental elements of masterpiece shopping and value of consumers to shopping satisfaction. Unpublished doctoral dissertation, Dongeui University, Busan, Korea.

Kim, C. S., \& Lee, J. (2011). A study on purchase behavior and design preference of luxury hand bag users aged 20 to 30 by lifestyle and age variable. Fashion \& Textile Research Journal, 13(6), 827-837. doi:10.5805/KSCI.2011.13.6.827

Kim, D. K. (1993). 현대마케팅원론 [Modern marketing principles]. Seoul: Pakyoungsa.
Kim, J. M. (2002). 명품의 조건 [Condition of luxury goods]. LG Business Insight, 677, 34-38.

Kim, J. Y. (2009). A study on the types and the characteristics of luxury consumption in Korean society. Unpublished doctoral dissertation, Yonsei University, Seoul, Korea.

Kim, N. M. (2015). A study on the self-esteem, appearance satisfaction, and clothing benefits pursuit of middle-aged consumers according to the gap between subjective age and real age. Unpublished master's thesis, Dongduk Women's University, Seoul, Korea.

Kim, R. D. (2007). 럭셔리 코리아 [Luxury country Korea]. Seoul: Miraebook.

Kim, S. A. (2011). The effects of individualismcollectivism on the shopping values and luxury purchase behavior. Unpublished master's thesis, Ewha Womans University, Seoul, Korea.

Kim, S.-S. (2006). The study about masstiege highend product (Part II): Focusing on shopping orientation. Journal of the Korean Society of Clothing and Textiles, 30(1), 12-19.

Kim, W. S. (1989). 마케팅정보시스템론: 시장조사론 [Marketing information system]. Seoul: Pakyoungsa.

Kim, Y. S. (2010). The influence of self-discrepancy on interpersonal satisfaction: Mediating effect of communication apprehension. Unpublished master's thesis, Ajou University, Gyeonggi-do, Korea.

Lee, B. H. (2016, January 6). 1인가구 시대 소비시장 이 변한다 [Consumer market of single-person household changes]. Financial News, Retrieved December 21, 2016, from http://www.fnnews.com/news/2016 01061722026776

Lee, I. J., \& Shin, H. J. (2001). An outward appearance of clothing study about effect of person perception. Journal of Human Environment and Art, 24, 203-220.

Lee, J. (2010). A study on luxury handbag purchase behavior for 20 s to 30 s aged Korean women. Unpublished master's thesis, Kyung Hee University, Gyeonggi-do, Korea. 
Lee, J. H. (2016, September 1). 남이 쓴 것도 좋아... 날개 단 명품 매출 [Chanel's economics]. Asia Economy News, Retrieved October 1, 2016, from http://www.asiae.co.kr/news/view.htm?idxno= 2016083018142258986

Lee, J.-H. (2010). Shopping orientations and attitudes according to the collaboration of luxury brands and of fast fashion brands. Unpublished master's thesis, Konkuk University, Seoul, Korea.

Lee, J.-H., Yoon, J.-Y., \& Cho, E.-A. (2009). Influences of physical self-efficacy by sport leisure activity on general self-efficacy and life satisfaction for women. Journal of the Korea Contents Association, 9(6), 379-389.

Lee, M. H. (1998). An effect of women college student's consumer characteristics and jeans' extrinsic cue on product evaluation. Unpublished doctoral dissertation, Ewha Womans University, Seoul, Korea.

Lee, S. M., \& Choi, S. H. (2001). 소비시장 고급화와 기업의 대응 [Consumer market upgrading and enterprise response]. Samsung Economic Research Institute, Retrieved October 1, 2016, from http:// www.seri.org/db/dbReptV.html?menu=db01\&pub o Lee, S. Y., Kim, J. W., \& Lee, J. S. (2004). Consciousness and purchasing attitude of fashion luxury: Focused on the college students in Daejeon. Korean Journal of Human Ecology, 13(6), 927-934.

Lee, S.-H., Lee, L., \& Jung, S. Y. (2003). The effects of variables on fashion luxury brand purchasing behavior. Journal of the Korean Society of Clothing and Textiles, 27(11), 1241-1251.

Lim, J. S. (2015). A study on the determinants of luxuriousness: With focus on product attributes corporate attributes, consumer motivation, and luxuriousness. Unpublished doctoral dissertation, Kangnam University, Gyeonggi-do, Korea.

Luxury goods. (n.d.). In Naver Korean dictionary. Retrieved September 20, 2016, from http://krdic. naver.com/detail.nhn?docid $=13503900$

Nia, A., \& Zaichkowsky, J. L. (2000). Do counterfeits devalue the ownership of luxury brands?. Journal of Product \& Brand Management, 9(7), 485-497. doi:10. 1108/10610420010351402

Online issue team. (2015, February 28). 포미족이 란... "'보여주기'식의 소비성향이 아닌 '가치소비' 에 중점" [What is the For-Me group]. The Asia Business Daily, Retrieved September 20, 2016, from http://www.asiae.co.kr/news/view.htm?idxno= 2015022815364259488

Park, C. S. (1991). Studies on family caregiving, clothing and nutrition of disabled elderly: (Part 2) Family relationship and caregiving of disabled elderly. Family and Environment Research, 29(3), 71-83.

Park, C.-W. (2012). Do motivation for luxury brand purchase and consumer's decision-making styles affect luxury product choice depending on the life attitude factors?. Unpublished master's thesis, Chung-Ang University, Seoul, Korea.

Park, H. J. (2012). The effects of conspicuous consumption on fashion \& beauty involvement and self-satisfaction. Unpublished doctoral dissertation, Kyungsung University, Busan, Korea.

Park, H. J., \& Jeon, K. S. (2004). Materialism and attitude toward purchasing foreign luxury brands: The moderating effect of consumer ethnocentrism. Journal of the Korean Society of Clothing and Textiles, 28(9/10), 1197-1207.

Park, H.-R., \& Hahn, D.-W. (2006). The integrated model to explain the behaviors of purchasing luxury brands of Korean women. The Korean Journal of Consumer and Advertising Psychology, $7(2), 195-226$.

Piak, I.-S. (2001). 20-30 woman's purchasing behavior and attributes evaluation and benefit imported fashion accessory based on self-monitoring. Unpublished master's thesis, Chung-Ang University, Seoul, Korea.

Purchase. (n.d.). In Naver encyclopedia. Retrieved September 20, 2016, from http://terms.naver.com/ entry.nhn?docId=923792\&cid=47326\&categoryId 


$$
=47326
$$

Rhee, E. Y. (1993). 복식의장학 [Costume design]. Seoul: Gyomoonsa.

Ryu, H. J. (2000). The study of self-image and shopping orientation by female's. Unpublished master's thesis, Silla University, Busan, Korea.

Self-satisfaction. (n.d.). In Naver Korean dictionary. Retrieved September 20, 2016, from http://krdic. naver.com/detail.nhn?docid $=31535500$

Shin, J. H. (2000). The influence of TV costume over costume purchase act of new generation: Focusing on star marketing. Unpublished master's thesis, Sookmyung Women's University, Seoul, Korea.

Shin, S. Y., \& Na, H. J. (2003). A study on the shopping orientation and the importance of store attributes of luxury brand consumer according to patronage store. The Research Journal of the Costume Culture, 11(4), 474-486.

Solomon, M. R. (2002). Consumer behavior: Buying, having, and being (5th ed). Upper Saddle River, NJ: Prentice Hall.

Song, J. E. (2008). The research about fashion luxury purchasing behavior according to adult female spending value. Unpublished master's thesis, Sookmyung Women's University, Seoul, Korea.

Sung, S. H. (2012). The influence of consumption value/attitude about luxury goods of adult women in consumption behavior and satisfaction level. Unpublished master's thesis, Chonnam National University, Gwangju, Korea.

Sung, Y.-S., Lee, J.-R., Shin, J.-R., \& Jung, Y. K. (2004). Consumer's response to the luxury and non-luxury brand logo: Perceptional, recognitional, emotional response by fMRI. The Korean Journal of Advertising, 15(4), 249-276.

Vigneron, F., \& Johnson, L. W. (1999). A review and a conceptual framework of prestige-seeking consumer behavior. Academy of Marketing Science Review, 1999(1). Retrieved from http://www.amsreview. org/articles/vigneron01-1999.pdf

Whang, S. M., Yoo, S. W., \& Chon, H. W. (2013). A study on the types of luxury consumption in Korean society. Journal of KSSSS, 27, 97-111.

Yang, J. W. (2013, July 25). [THE HISTORY OF LUXURY] 대한민국에서 명품이란 이름으로 살 아온 30년 [The history of luxury]. The Korea Economic Magazine, Retrieved October 1, 2016, from http://magazine.hankyung.com/money/apps/ news?popup $=0 \&$ nid $=02 \&$ c $1=2 \&$ nkey $=201307230$ 0098072122\&mode $=$ sub_view

Yoon, S. W. (2013). A study on brand attachment, brand commitment, and repurchase intention following the lifestyles of luxury jewelry consumers. Unpublished doctoral dissertation, Kyonggi University, Gyeonggi-do, Korea.

Yoon, S.-W., \& Han, J.-H. (2008). An exploratory study on market segmentation of luxury brand consumers based on customer value. Journal of Consumer Studies, 19(4), 135-159.

Zhao, M.-N. (2015). The effects of chemyon (social-face) sensitivity, vanity and conspicuous consumption on brand attitude toward fashion luxury goods: $A$ comparative study of Korean and Chinese female university students. Unpublished master's thesis, Chonnam National University, Gwangju, Korea. 